\title{
Understanding who cyberloafs from the self-control perspective: A study in the public service sector
}

\author{
Aminah Ahmad ${ }^{1}$, Zoharah Omar ${ }^{1,2, *}$ \\ ${ }^{1}$ Institute for Social Science Studies, Universiti Putra Malaysia, Serdang, Selangor, Malaysia \\ ${ }^{2}$ Department of Professional Development and Continuing Education, Faculty of Educational Studies, Universiti Putra Malaysia, \\ Serdang, Selangor, Malaysia
}

\section{A RT I C LE IN F O}

\section{Article history:}

Received 14 March 2017

Received in revised form

15 June 2017

Accepted 15 July 2017

Keywords:

Cyberloafing

Gender

Age

Self-control theory

Public service sector

\begin{abstract}
A B S T R A C T
The aim of this study is to understand cyberloafing behavior of employees from the self-control perspective, and to examine differences in cyberloafing according to gender and age, and the gender-age interaction effect. We used survey questionnaires to collect data from 260 Malaysian employees in the public service sector. Our results indicate that the employees engage in cyberloafing with males cyberloafing more than females, irrespective of age. This study contributes to cyberloafing behavior literature by providing an explanation of gender difference in cyberloafing using the self-control theory. The non-significant results on difference in cyberloafing according to age and gender-age interaction effect are discussed. Implications of these results for research and organizational Internet policies and practices are presented.
\end{abstract}

C 2017 The Authors. Published by IASE. This is an open access article under the CC BY-NC-ND license (http://creativecommons.org/licenses/by-nc-nd/4.0/).

\section{Introduction}

As a form of deviant behavior at work, cyberloafing is considered counterproductive since its activities such as browsing and emailing deter employees from completing tasks at work (Chen and Lim, 2012). Robinson and Bennett (1995) categorized deviant behavior at work into two categories of dimensions -- minor and serious dimensions, and the interpersonal or organization focused dimensions. The organization focused minor form of cyberloafing includes activities such as checking one's personal email and visiting mainstream news, while the serious form includes activities such as online gambling and downloading music (Blanchard and Henle, 2008). The taxonomy of cyberloafing by Mastrangelo et al. (2006) divided this deviant behavior into nonproductive and counterproductive computer use. Nonproductive computer use refers to the use of computer at work for activities that are non-beneficial but nondestructive to the organization. Examples of such activities include chatting, gaming, emailing, shopping, and viewing online media. Counterproductive computer use refers to the use of computer at work for activities that could be at odds

\footnotetext{
* Corresponding Author.

Email Address: zoharah@upm.edu.my (Z. Omar)

https://doi.org/10.21833/ijaas.2017.08.017

2313-626X/C) 2017 The Authors. Published by IASE.

This is an open access article under the CC BY-NC-ND license

(http://creativecommons.org/licenses/by-nc-nd/4.0/)
}

with the organization's goals. Examples of such activities include distributing or downloading pornography, and producing computer viruses. Another frequently used label for cyberloafing is cyberslacking (O'Neill et al., 2014).

Researchers found that cyberloafing has positive outcomes on employees since it can reduce stress, boredom and fatigue, and increase job satisfaction, recreation and recovery (Vitak et al., 2011), besides adding variety to everyday activities (Lim and Chen, 2012). Coker (2013) found that Internet leisure surfing helps refresh employees' engagement at work more than other forms of less enjoyable breaks. Taking occasional breaks from work is necessary since these breaks permit employees to restore their energy which is vital for enhancing their work performance (Chen and Lim, 2012). There are employees who cyberloaf to acquire information for self-development as well as professional advancement, or accomplish work-life balance (Anandarajan et al., 2006).

In spite of the fact that cyberloafing can help enhance employees effectiveness, it might likewise draw employees to engage in counterproductive work behaviors (Jia et al., 2013). Cyberloafing can bring about threats including bandwidth loss, computer viral infection, legal liabilities (Lim, 2002), and reduced involvement at work (Liberman et al., 2011). Employee use of Internet access for non-work related activities tend to result in lower job performance (Bock and Ho, 2009). Because of these negative consequences, researchers are more 
concerned to understand cyberloafing behavior among employees.

Despite the empirical evidence on negative effects of deviant behavior including cyberloafing on organizational performance, published work on cyberloafing within the Malaysian context especially in the public sector has been sparse. Past studies on deviant behavior at work in Malaysia did not focus on cyberloafing specifically, but on interpersonal and organizational deviance (Ahmad et al., 2016; Nasurdin et al., 2014). It must be acknowledged that there is an increase in the number of research on cyberloafing in other countries. However, few studies have explained cyberloafing from the selfcontrol perspective. Furthermore, the samples for previous cyberloafing studies consisted of mixed groups of working adults (Huma et al., 2017; Jia et al., 2013) and education institutions (Baturay and Toker, 2015; Blanchard and Henle, 2008) and to the best of our knowledge none in the non-education public service organizations.

\section{Self-control theory}

The self-control theory, developed by Gottfredson and Hirschi (1990), is a theory that explains how lack of self-control serves as an important factor behind deviant behavior. Based on this theory, deviant behavior is an expression of low self-control. Hence, low self-control individuals tend to engage in deviant behavior because such acts result in the immediate fulfillment of their desires. Additionally, low self-control individuals tend to lack persistence and their involvement in deviant behavior points to their inclination for immediate pleasure and failure to defer pleasure. It can be argued that individuals tend to engage in deviant behavior such as cyberloafing to seek pleasure since it is an easy act and a simple means of satisfying one's desires. Vazsonyi and Belliston (2007) found that self-control is a more important predictor of deviant behavior compared to other predictors.

According to Gottfredson and Hirschi (1990), selfcontrol is a factor that is developed since childhood through effective parenting, established at a young age, and remains stable at the adult stage as well as plays an important role in explaining the differences in deviant behavior across individuals. Specifically, it has been noted that consistent parental monitoring and discipline, together with love, leads to the establishment of self-control. Through parental socialization females tend to develop greater selfcontrol as compared to males, and self-control develops with age.

Based on this theory, it has been argued that because most people regard females as in more danger than males with respect to misbehavior, parents tend to monitor the behavior of girls more carefully than that of boys (Tittle et al., 2003). This excess monitoring may continue into adulthood as society attempts to lessen opportunities for misbehavior among females. Since social acceptability is closely attached to female role, care providers tend to socialize girls in such a way that misbehavior is reduced. Hence, females tend to develop greater self-control as compared to males, and they tend to engage less in deviant behavior.

\section{Literature review and hypothesis development}

\subsection{Gender and cyberloafing}

To understand Internet usage behaviors including cyberloafing, gender plays an important role. Chen and Lim (2012) studied cyberloafing among alumni members selected from a large Asian university and found that males tend to cyberloaf more than females. Similar results were found by Jia et al. (2013) who studied cyberloafing among a diverse set of working adults in the United States. In another study among American employees, there exists gender differences in cyber-loafing in which females tend to engage more in cyberloafing with respect to variety and frequency of loafing (Vitak et al., 2011). In a Turkish educational setting, Baturay and Toker (2015) found that males cyberloafed more than females. In general, the time that males spent in using the internet was more than females and thus males were more likely to experience greater Internet abuse risk than females (Stavropoulos et al., 2013). The literature and the self-control theory seem to support the notion that gender difference exists in cyberloafing with males engaging in it more than females. Hence, the following hypothesis was tested.

H1: Male employees tend to cyberloaf at work more than female employees.

\subsection{Age and cyberloafing}

The difference in cyberloafing by age has been studied by researchers. A study by Jia et al. (2013) has shown that younger employees engage in cyberloafing more than older employees. Similarly, a study by Vitak et al. (2011) has also revealed that cyberloafing frequency is greater among younger than older employees. The association between cyberloafing and age has been demonstrated by Ugrin and Pearson (2013) who studied North American employees and found that a greater number of older employees viewed social networking as abusive at work more than their younger counterparts, and hence younger individuals were more likely to misuse the Internet more seriously than the older individuals (Mastrangelo et al., 2006). The use of Internet was found to be more common among individuals aged between late 20s to early 30s (Reed et al., 2005). Weiser (2000) found that the use of Internet for emailing was greater among the younger age groups, but appeared to decrease gradually among individuals in the 41-and-older group.

Despite the fact that studies have demonstrated that younger workers cyberloaf more than older 
workers, an investigation by Restubog et al. (2011) among administrative university employees has shown conflicting results. They found that older employees engaged more in cyberloafing than younger employees. Generally, researchers have demonstrated that cyberloafing differs by age, and most studies are supportive of the notion that those who loaf the Internet more are the younger employees. Based on the self-control theory as earlier discussed and previous research findings, we tested the following hypothesis.

H2: Younger employees tend to cyberloaf at work more than older employees.

\subsection{Gender-Age interaction and cyberloafing}

Few studies have tested gender and age interaction on cyber-related behaviors. Weiser (2000) assessed gender differences in the use of specific Internet applications among a younger age group sample (college students) and a more heterogeneous age group of online sample. Gender differences in specific Internet application preferences were found. Although age-related patterns in specific uses of the Internet were found, none of the gender and age interaction effects were significant, suggesting that differences in males' and females' patterns of Internet use differed little as a function of age. Similarly, Thayer and Ray (2006) explored variations in online communication preferences across gender and age and found no significant interaction effect of gender and age. Helsper (2010) investigated the role played by generation (eight age groups) in relation to gender differences in breadth of Internet use (number of online activities). The breadth or range of Internet activities undertaken by older Internet users was narrower than younger users, and that females and males differed in range of Internet use for the older age groups.

The effect of gender-generation interaction in breadth of Internet use was significant. The limited studies on gender-age interaction on cyber-related behaviors produced mixed results, and to the best of our knowledge, the gender-age interaction effect on employee cyberloafing behavior has not been reported yet and hence we tested the following hypothesis.

H3: There is a significant gender and age interaction effect on cyberloafing.

\section{Methodology}

\subsection{Sample and procedure}

Two hundred and sixty-one employees from a public service organization in Malaysia constituted the survey sample. Self-administered questionnaire was used to gather data. We chose the public organization since in spite of the government's commitment to enhance employee civility through the formation of the Public Complaints Bureau in 2000 , the civility can still be improved by reducing employees' negative behavior (Siddiquee, 2006).

In this survey, the questions were in two languages -- English and Malay, with Malay being the first language and English the second language of Malaysians. Originally, the questions were in English, and before data gathering they were translated to Malay and then back translated to ensure that their meanings were comparable. The participants were assured of the confidentiality of all their responses.

The participants' mean age was 33.63 years $(\mathrm{SD}=$ 8.41), and there were 153 (58.8\%) females and 107 (41.2\%) males. Of the 260 participants, 127 (49\%) were executives while 133 (51\%) non-executives, and $179(68.8 \%)$ had tertiary education and the rest $81(31.2 \%)$ secondary education.

\subsection{Measures}

Cyberloafing was measured using nine items adapted from two cyperloafing scales by Blanchard and Henle (2008) and Lim (2002), two and six items, respectively. A seven-point response choices extending from 1 (never) to 7 (very often) were utilized. The activities include those which have not been included by the pioneering work of Lim (2002), such as writing and reading blogs, and instant messaging which have become commonplace.

In this study, we conducted the social desirability bias test to address the possible limitation arising from responses that might not indicate the actual frequency of engagement in cyberloafing. In this study, the Crowne-Marlowe ten-item short version social desirability scale (Crowne and Marlowe, 1960) was used with true and false response options. Employees were requested to indicate whether the statements depict themselves. A sample item is "When I don't know something, I don't at all mind admitting it". We assigned a score of 0 to true and 1 to false option, and reverse coded negative statements. Social desirability test scores may differ among respondents as well as in various settings. We summated the scores to determine the social desirability bias of each respondent and a higher score shows a greater social desirability bias. We then computed the means and standard deviations of the scores. The social desirability bias mean score was low $(M=4.43, S D=1.66)$, hence indicative of a low response bias in the sample.

\subsection{Data analysis}

We determined the reliability of the scale and obtained an acceptable Cronbach alpha coefficient of .96. Means and standard deviations for the scale items were computed. We examined the difference by gender (male and female) and age $(\leq 30$ and $>30$ years), and the gender-age interaction effect using ANOVA. 


\section{Results and discussion}

Table 1 presents the cyberloafing item means and standard deviations. Overall, the extent of cyberloafing was moderate $(M=3.71, S D=1.85)$. The item "Receive, send, and check non-work related email" had the highest mean $(M=4.00, S D=1.86)$, while the item "Browse employment website"

Table 1: Means and standard deviations of items measuring cyberloafing

\begin{tabular}{ccc}
\hline Item & $\mathrm{M}$ & $\mathrm{SD}$ \\
\hline $\begin{array}{c}\text { Receive, send, and check non-work related email } \\
\text { Browse non-work related website (e.g.: }\end{array}$ & 4.00 & 1.86 \\
entertainment, political, sports, and etc.) & 3.85 & 1.82 \\
Participate in non-related work chat rooms and & 3.83 & 2.07 \\
instant messaging. & 3.82 & 2.05 \\
Browse social networking. (e.g. Facebook, Twitter) & 3.73 & 2.13 \\
Write and read blogs & 3.57 & 2.27 \\
Play games online & 3.57 & 2.25 \\
Download movies and music & 3.56 & 2.17 \\
Shop online for personal goods & 3.44 & 2.22 \\
Browse employment website & 3.71 & 1.85 \\
\hline Overall & &
\end{tabular}

$(M=3.44, S D=2.22)$ had the lowest mean. Overall, the employees were more involved in nonwork related emailing, browsing non-work related websites, instant messaging and social networking. They engaged to a lesser extent in playing games online, downloading movies and music, shopping online, and browsing employment websites Table 2 presents the means and standard deviations of cyberloafing by gender and age.

Table 2: Summary statistics of cyberloafing by gender and

\begin{tabular}{ccccc}
\multicolumn{5}{c}{ age } \\
Variable & Category & $\mathrm{N}$ & $\mathrm{M}$ & $\mathrm{SD}$ \\
\hline \multirow{2}{*}{ Gender } & Male & 107 & 4.20 & 1.94 \\
& Female & 153 & 3.36 & 1.70 \\
\multirow{2}{*}{ Age } & $\leq 30$ & 130 & 3.82 & 1.75 \\
& $>30$ & 130 & 3.59 & 1.94 \\
\hline
\end{tabular}

Results of ANOVA revealed that the main effect of gender on cyberloafing was significant $\left(\mathrm{F}_{1,256}=\right.$ 13.87, $\mathrm{p}=.00$ ) such that male employees cyberloafed at work more than female employees, thus supporting H1. However, the main effect of employee age on cyberloafing was not significant $\left(\mathrm{F}_{1,256}=1.16\right.$, $\mathrm{p}=.28$ ) and therefore, this does not support $\mathrm{H} 2$ on age difference in cyberloafing (Table 3). The interaction effect of gender and age on cyberloafing was not significant $\left(F_{1,256}=.12, p=.73\right)$ such that for both male and female employees, the extent of cyberloafing did not differ significantly irrespective of whether they are in the younger or older age category. The results indicate that the predictive power of gender on cyberloafing was not contingent upon employee age category. Hence, the results do not support the hypothesis that cyberloafing is dependent on age-gender interaction (H3).

The significant difference by gender is in line with the results of previous studies (Vitak et al., 2011; Lim and Chen, 2012; Jia et al., 2013; Baturay and Toker, 2015) whereby males were found to be more significantly involved in cyberloafing than females. From the self-control perspective, females tend to have stronger self-control than males and hence engage less in deviant behavior. This is so because the danger associated with misbehaving among females is perceived as greater than among males, and thus girls are monitored more closely by their parents than boys with the hope that they do not engage in deviant behavior.

Table 3: ANOVA for cyberloafing by gender and age

\begin{tabular}{cccccc}
\hline Variable & $\mathrm{df}$ & $\mathrm{SS}$ & $\mathrm{MS}$ & $\mathrm{F}$ & $\mathrm{p}$ \\
\hline Gender & 1 & 45.15 & 45.15 & 3.87 & .00 \\
Age & 1 & 3.79 & 3.79 & 1.16 & .28 \\
Genderx Age & 1 & 0.39 & 0.39 & 0.12 & .73 \\
Error & 256 & 833.54 & 3.26 & & \\
Total & & 882.87 & & & \\
\hline
\end{tabular}

Previous studies have provided several explanations for the gender difference in cyberloafing. Males were more confident than females in the use of Internet (Weiser, 2000; Hargittai and Shafer, 2006). Women tend to view cyberloafing as an unproductive activity because of their greater anxiety and inability to take advantage of the information available from the Internet (Chen and Lim, 2012), and thus women tend to cyberloaf less than men. Men tend to view cyberloafing at work as positive and hence are more likely to cyberloaf (Lim and Chen, 2012).

Although technological abilities, confidence in Internet use, higher web familiarity as well as positive perceptions could be associated with greater engagement in cyberloafing, a study conducted by Restubog et al. (2011) on administrative and non-academic university employees revealed that low self-control employees are more probable to engage in cyberloafing. It is possible that despite these positive qualities, males tend to be less successful in controlling themselves from engaging in cyberloafing. We regard our results on gender difference in cyberloafing as supportive of the self-control theory.

However, the non-significant difference in cyberloafing according to age does not seem to support the self-control theory. Although it is acknowledged that self-control may improve as individuals grow older (Gottfredson and Hirschi, 1990), and researchers have acknowledged that there are empirical support for the age-deviance relationship (Loeber and Farrington, 2014; Farrington et al., 2013), Tittle et al. (2003) found that self-control could not explain misbehavior among different age groups. As cyberloafing behaviour is often engaged in when employees have access to the Internet at work, this could serve as a situational trigger for the behavior (Weatherbee, 2014), and in this study, since the opportunities may be equally available to younger and older employees, it is therefore likely that the tendency to cyberloaf among both age groups is not significantly different.

Similarly, it can be argued that since technological skills is associated with the Internet abuse, and younger employees have greater skills, thus increasing the probability of their engagement in deviant behavior (Stavropoulos et al., 2013), it is 
probable that the older age group has gradually catched up with the lag in IT skills and hence are as computer savvy as their younger counterparts. The acquired skills may serve as another possible precondition that drives low self-control older employees to engage in cyberloafing.

Studies conducted on employees have shown, to a certain extent, the benefits of blocking black listed websites using reminders to reduce the cyberloafing behavior (Glassman et al., 2015), and employing monitoring systems to monitor the Internet activities and employing punishments on employees who have been caught cyberloafing (Ugrin and Pearson, 2013). However, studies by Tittle et al. (2003) and Restubog et al. (2011) revealed that low self-control employees had greater propensity to engage in deviant behavior, and monitoring low selfcontrol employees through, for example, tracking employees' email and other Internet activities followed by disciplinary actions, may help organizations to deter cyberloafing. Additionally, a study by Vazsonyi and Belliston (2007) has also found that self-control is a more important predictor of deviant behavior, compared to other predictors. According to Vitak et al. (2011), self-control, to a certain extent, can be restored by making employees aware of the linkage between deviant behavior and potential negative work outcomes. Hence, employers need to create awareness of the negative consequences of cyberloafing to deter this behavior.

There are a few probable limitations of this present study. Our results may be vulnerable to problems associated with common method variance since our data were gathered through self-reports. However, since this study examined individual experiences in cyberloafing, a deviant behavior, it is acceptable to use self-report measures. Besides, as indicated by Spector (2006), the problem of common method variance has been for the most part overstated. We have a few reasons for believing that the problem pertaining to social desirability response is not a major limitation in this present study. First, the anonymous data obtained probably reduced the problem associated with social desirability responses. Second, the social desirability bias test that we conducted using the scale by Crowne and Marlowe (1960) produced a mean score of 4.42 showing a low response bias. Besides selfreport, the sample, consisting of Malaysian employees in the public service sector, may pose another limitation to this study and this may affect the generalizability of the findings. There is, therefore, a need to conduct studies on employees from the private industries before the findings can be generalized to other populations.

\section{Conclusion}

We conclude that irrespective of age, employees engage in cyberloafing and the engagement of males in cyberloafing is more than females. The gender difference in cyberloafing may be explained by the self-control theory. Employee engagement in cyberloafing has significant implications for employers since it has turned out to be a pervasive employee problem for organizations. It implies the need for organizations to monitor the use of the Internet by employees and to detect illegal usage to curb this problem. As for researchers, when examining factors that contribute to cyberloafing, they may need to consider self-control as one of the possible factors, and gender as a likely moderating or a contigency variable. The non-significant findings on difference in cyberloafing by age and the genderage interaction effect suggest the need to further examine this phenomenon.

\section{Acknowledgement}

This work (Project No. 06-02-12-2251RU) was financially supported by the Research University Grant Scheme of Universiti Putra Malaysia under Grant number 06-02-12-2251RU. The authors are thankful to Universiti Putra Malaysia for the support.

\section{References}

Ahmad A, Omar Z, Radzali FM, and Saidu MB (2016). Religiosity and emotional stability as determinants of citizenship and deviant behavior at work. The Social Sciences, 11(22): 55205525 .

Anandarajan M, Paravastu N, and Simmers CA (2006). Perceptions of personal Web usage in the workplace: A Q-methodology approach. Cyber Psychology Behavior, 9(3): 325-335.

Baturay MH and Toker S (2015). An investigation of the impact of demographics on cyberloafing from an educational setting angle. Computers in Human Behavior, 50: 358-366.

Blanchard A and Henle C (2008). Correlates of different forms of cyberloafing: The role of norms and external locus of control. Computers in Human Behavior, 24(3): 1067-1084.

Bock GW and Ho SL (2009). Non-work related computing (NWRC). Communications of the ACM, 52(4): 124-128.

Chen DJ and Lim VK (2012). Strength in adversity: The influence of psychological capital on job search. Journal of Organizational Behavior, 33(6): 811-839.

Coker BL (2013). Workplace Internet leisure browsing. Human Performance, 26(2): 114-125.

Crowne DP and Marlowe D (1960). A new scale of social desirability independent of psychopathology. Journal of Consulting Psychology, 24(4): 349-354.

Farrington DP, Piquero AR, and Jennings WG (2013). Offending from childhood to late middle age: Recent results from the Cambridge Study in delinquent development. Springer Science and Business Media, Berlin, Germany.

Glassman J, Prosch M, and Shao BBM (2015). To monitor or not to monitor: Effectiveness of a cyberloafing countermeasure. Information and Management, 52(2): 170-182.

Gottfredson MR and Hirschi T (1990). A general theory of crime. Stanford University Press, Palo Alto, USA.

Hargittai E and Shafer S (2006). Differences in actual and perceived online skills: The role of gender. Social Science Quarterly, 87(2): 432-448.

Hayer SE and Ray S (2006). Online communication preferences across age, gender, and duration of internet use. CyberPsychology and Behavior, 9(4): 432-440.

Helsper EJ (2010). Gendered internet use across generations and life stages. Communication Research, 37(3): 352-374. 
Huma ZE and Hussain S, Thurasamy R, and Malik MI (2017). Determinants of cyberloafing: A comparative study of a public and private sector organization. Internet Research, 27(1): 97 117.

Jia H, Jia R, and Karau S (2013). Cyberloafing and personality: The impact of the big five traits and workplace situational factors. Journal of Leadership and Organizational Studies, 20(3): 358365.

Liberman B, Seidman G, McKenna K, and Buffardi L (2011). Employee job attitudes and organizational characteristics as predictors of cyberloafing. Computers in Human Behavior, 27(6): 2192-2199.

Lim VK (2002). The IT way of loafing on the job: Cyberloafing, neutralizing and organizational justice. Journal of Organizational Behaviour, 23(5): 675-694.

Lim VK and Chen DJ (2012). Cyberloafing at the workplace: gain or drain on work? Behaviour and Information Technology, 31(4): 343-353.

Loeber R and Farrington DP (2014). Age-crime curve. In: Bruinsma G and Weisburd D (Eds.), Encyclopedia of criminology and criminal justice: 12-18. Springer, New York, USA.

Mastrangelo P, Everton W, and Jolton JA (2006). Personal use of work computers: Distraction versus destruction. CyberPsychology and Behaviour, 9(6): 730-741.

Nasurdin AM, Ahmad NH, and Razalli AA (2014). Politics, justice, stress, and deviant behaviour in organizations: An empirical analysis. International Journal of Business and Society, 15(2): 235-254.

O'Neill TA, Hambley LA, and Chatelier GS (2014). Cyberslacking, engagement, and personality in distributed work environments. Computers in Human Behavior, 40: 152-160.

Reed K, Doty DH, and May DR (2005). The impact of aging on selfefficacy and computer skill acquisition. Journal of Managerial Issues, 17(2): 212-228.

Restubog SLD, Garcia PRJM, Toledano LS, Amarnani RK, Tolentino LR, and Tang RL (2011). Yielding to (cyber)-temptation: Exploring the buffering role of selfcontrol in the relationship between organizational justice and cyberloafing behavior in the workplace. Journal of Research in Personality, 45(2): 247 251.

Robinson SL and Bennett RJ (1995). A typology of deviant workplace behaviors: A multidimensional scaling study. Academy of Management Journal, 38(2): 555-572.

Siddiquee NA (2006). Public management reform in Malaysia. International Journal of Public Sector Management, 19(4): 339-358.

Spector PE (2006). Method variance in organizational research truth or urban legend?. Organizational Research Methods, 9(2): 221-232.

Stavropoulos V, Alexandraki K, and Motti-Stefanid F (2013). Flow and telepresence contributing to internet abuse: Differences according to gender and age. Computers in Human Behavior, 29(5): 1941-1948.

Tittle CR, David WA, and Grasmick HG (2003). Gender, age, and crime/deviance: A challenge to self-control theory. Journal of Research in Crime and Delinquency, 40(4): 426-453.

Ugrin JC and Pearson JM (2013). The effects of sanctions and stigmas on cyberloafing. Computers in Human Behavior, 29(3): 812-820.

Vazsonyi AT and Belliston LM (2007). The family $\rightarrow$ low selfcontrol $\rightarrow$ deviance: A cross-cultural and cross-national test of self-control theory. Criminal Justice and Behavior, 34(4): 505 530.

Vitak J, Crouse J, and LaRouse R (2011). Personal Internet use at work: Understanding cyberslacking. Computers in Human Behavior, 27(5): 1751-1759.

Weatherbee DE (2014). International relations in Southeast Asia: The struggle for autonomy. Rowman and Littlefield, Lanham, Maryland, USA.

Weiser EB (2000). Gender differences in Internet use pattern and Internet application preferences: A two sample comparison. CyberPsychology and Behavior, 3(2): 167-178. 